\title{
Impact of Immediate Nursing Care for Hepatic Encephalopathy Patients to Reduce Gastrointestinal Complication on Patient's Outcome in Intensive Care Unit at Main Assiut University Hospital
}

\author{
Sanaa Mustafa Sayed, Mona Aly Mohammed, Mervat Anwar AbdEl-Aziz and Nabila Faiek Ameen \\ B.S. Professional Nurse in Quality Unit Assiut University Hospital. \\ Lecturer in Critical Care Nursing Department, Faculty of Nursing, Assiut University \\ Professor of internal medicine \& gastroenterology, Faculty of Medicine, Assiut University
}

\begin{abstract}
:
Immediate care is an essential nursing function to identify early deterioration in mental status. The nurse monitors the patient's mental status closely .Oxygen is administered if oxygen de-saturation occurs. The nurse monitors for fever or abdominal pain. This may be a signal the onset of bacterial peritonitis or other infection. Aim of the study was to investigate the immediate nursing care for hepatic encephalopathy patients' to reduce gastrointestinal complication on patient's outcome. Subject and methods descriptive research design was used to conduct this research. The sample of this study was consisted of 60 patients. Tools used in this study comprised three main tools. Tool 1:- patients assessment sheet. Tool 11:-fluid intake and| output and nutrition assessment. Tool 111:- Evaluation sheet. The main result:- Regarding West- haven criteria there was a significant decrease for the studied group from $1^{\text {st }}$ day and $2^{\text {nd }}$ day. There were statistical significance differences between the two days. Regarding complete blood picture; WBC in the studied group showed that significant decrease on $2^{\text {nd }}$ day. Fluid intake \& output in the studied group showed that significant increase on $2^{\text {nd }}$ day. Conclusion:- Applied immediate nursing care significant to reduce gastrointestinal complication in hepatic encephalopathy patients and improve the patient's outcome. Therefore, it is recommended to providing nutritional counseling for all patients with hepatic encephalopathy, continuing Educational Nursing Programmes to access the high quality of care.
\end{abstract}

Keywords: Hepatic encephalopathy, immediate nursing care, patient's outcome.

\section{Introduction:}

Hepatic encephalopathy can be broadly defined as the alterations in mental state and cognitive function that occur in liver failure. The course of both acute and chronic liver failure can be complicated by the development of neurologic dysfunction. In acute liver injury, encephalopathy portends a poor prognosis and death can occur as a result of neurologic complications. In patients with cirrhosis, encephalopathy is a cause of major morbidity, and when chronic, can be incapacitating condition. The latter is especially problematic in subjects awaiting liver transplantation, in which chronic hepatic encephalopathy is increasingly noted (Banco et al, 2006).

Hepatic encephalopathy (also known as Porto systemic encephalopathy) is the occurrence of confusion, altered level of consciousness and coma as a result of liver failure. In the advanced stages it is called hepatic coma. It may ultimately lead to death (Mc Cornville et al, 2010).

Management of precipitating factors The identification and correction of any precipitating events is of paramount importance .If symptoms do not improve then a search for second complication, most often occult infection, needs to be made .
Gastrointestinal hemorrhage should be managed vigorously with antibiotics, vasoactive drugs, an endoscopic therapy; anemia should be corrected early and blood pressure maintained to prevent further hepatic and renal insults. Infections, most commonly pulmonary, urinary or peritoneal should be treated promptly using appropriate antibiotics. Electrolyte abnormalities should be managed by discontinuing diuretics and correcting the deficits, as appropriate. Deterioration in renal function should be corrected, if possible, by stopping diuretics, increasing the circulating volume to maintain renal perfusion and discontinuing any potentially nephrotoxic drugs. Sedative should be stopped and their effects reversed, if possible (Dooley et al, 2011).

When endoscopy isn't available to treat variceal hemorrhage, balloon tamponade can be used. It can also be used as an adjunct to pharmacotherapy, especially when bleeding is difficult to control. The device used most often is the Sengstaken-Blakemore tube (SBT), which has both esophageal and gastric balloons; when inflated, these compress the varices and decrease esophageal blood flow. To reduce the patient's risk for aspiration, the stomach might be lavaged with sterile saline to remove blood before 
insertion; however, there's an increased risk of additional bleeding due to trauma from the nasogastric tube. Although balloon tamponade controls acute hemorrhage in more than $80 \%$ of cases, rebreeding upon deflation is common (Garcia \& Lim, 2009).

The critical care nurse is responsible for maintaining a safe environment to prevent injury, bleeding, and infection. The nurse administers the prescribed treatments and monitors the patient for the numerous potential complications. The nurse also communicates with patient's family, to inform them about the patient's status, and supports them by explaining the procedures and treatment that are part of the patient's care. If the patient recovers from hepatic encephalopathy and coma,

rehabilitation is likely to be prolonged. Therefore, the patient and family will require assistance to understand the causes of this sever complication and recognize that it may recur (Smeltzer et al, 2008).

Protection of the patient's dignity during altered level of consciousness LOC, simple measures such as providing privacy and speaking to the patient during nursing care activities preserve the patient's dignity. Not speaking negatively about the patient's condition or prognosis is also important, because patients in a light coma may be able to hear. The comatose patient has an increased need for advocacy, and the nurse is responsible for seeing that these advocacy needs are met (Hickey, 2003).

Nursing measures to prevent constipation should be instituted to decrease ammonia production. Drugs, laxative, and enemas should be given as ordered. Encouragement of fluids may also help if not contraindicate. The patient should not strain at stool because this may cause bleeding of hemorrhoidal varices. Any GI bleeding may worsen the coma. The patient who is taking lactulose should be assessed for diarrhea and excessive fluid and electrolyte losses (Lewis et al, 2007).

Nutrition is an important consideration in the patient with cirrhosis. Foods and fluids high in carbohydrate should be synthesizing and strong glucose. The patient may require tube feedings if an adequate diet cannot be ingested (Lewis et al, 2007). Vegetablebased protein is better tolerated by patients with cirrhosis than meat -based protein. Vegetable-based protein food have a high fiber content, which increases intestinal transit time and Colonic motility and enhances intestinal nitrogen clearance (Parkash\& Mullen, 2010). Vegetable protein also reduces colonic $\mathrm{pH}$, which prevents ammonia from being absorbed in the gut. (Bajaj, 2010).

\section{Subject And Methods}

Aim of the study:-

to investigate immediate nursing care for hepatic encephalopathy patients' to reduce gastrointestinal complication on patient's outcome.

Research design:

Descriptive research design was utilized in the study. Variables:

Dependant variable was patient's outcome (vital signs and decrease complication)

Independent variable was immediate nursing care A- Setting of the study:

The study was conducted in intensive care unit of gastroenterology and hepatology in internal medicine department at main Assiut University Hospital.

B- Sample:

A convenience sample of 60 adult male \& female patients who were diagnosed as hepatic encephalopathy.

Hypotheses:

There was significant reduction in gastrointestinal complications among the study group.

Criteria of the sample:

Inclusion criteria:_The patients admitted in Intensive Care Unit or Gastroenterology unit and Hepatology in internal medicine department with diagnosis of hepatic encephalopathy.

Exclusion criteria:

Patient with renal failure, head trauma, brain abscess, neurologic problem (meningitis, encephalitis) and multiple system failure.

C- Tools:

Three tools were used to collect the data in the study developed by the researcher based on the reviewing related literature.

Tool one: patients assessment sheet

This tool was developed by the researcher to assess the patient's condition and compromised four parts which includes:

Part (1) : Assessment of socio-demographic and clinical data:

This part included patient's related data such as patient's age, condition on discharge, medical diagnosis, west- Haven Criteria, Ascites and abdominal girth developed by the researcher on admission (base line) and $2^{\text {nd }}$ days.

Part (2) : Assessment of gastrointestinal complication

It included vomiting, constipation, diarrhea, hematemesis and melena, developed by the researcher on admission (base line) for two days every shift. 
Part (3) : precipitating factors of hepatic encephalopathy

It included gastrointestinal bleeding, electrolyte imbalance, dehydration, constipation, vomiting, excess protein load and fever.

Part (4) : Assessment of vital signs

This part included (temperature, pulse, respiratory rate, heart rate, blood pressure and mean arterial pressure) developed by the researcher on admission (base line) for two days every 2 hours.

Tool two:

It included four parts

\section{Part (1) : Arterial blood gas}

This part was used to assess (Po2), blood $\mathrm{PH}$, bicarbonate (Hco3), Carbon dioxide (Co2).

Part (2) : Assessment of fluid intake, fluid output and enema

Developed by the researcher on admission (base line) for two days.

\section{Part (3) : Laboratory investigation}

This part was used to assess the selected hematological studies and hepatitis markers.

Part (4) : nutritional assessment

This tool was developed by the researcher to assess nutritional status which include

- Subjective Global Assessment (SGA)

- Anthropometric measurement

Third tool :

Evaluation sheet of hepatic encephalopathy patients

This part was developed by the researcher to evaluate hepatic encephalopathy patients: by use (Tool 1, 11)

Methods:

- Official permission from the faculty of nursing to conduct the study was delivered to the hospital authorities in Assiut university hospital and approval to conduct this study was obtained.

- Permission to conduct the study was obtained from the head of the intensive care unit of gastroenterology and hepatology in internal medicine department after explanation of the aim of the study.

- Ethical considerations the nature and purpose of the study was explained to every relative of the patient.

- Informed consent was obtained from every relative of the patient

- The anonymity and confidentiality of responses, voluntary participation and the right to refuse to participate in study were emphasized to subjects.

- The tools used in this study were developed by the researcher based on reviewing the relevant literature.

- The tools were reviewed by jury for face the clarity , feasibility, applicability, reliability and the content validity of the tools and all the necessary modifications were done.

- The jury members were five experts representing related content area. This included 3 medical staff and 2 nursing staff from faculty of nursing and the necessary modifications were done.

- A pilot study was conducted on 6 patients to test the feasibility and applicability of the tools, These selected patients were excluded from the actual study.

Statistical analysis:

All data were recorded in a special chart for every patient. All entered data were verified for any errors using Statistical Package for Social Sciences (SPSS) version19 for windows. Descriptive statistics as number, percentage, means and standard deviation. Data were collected, tabulated and statistically analyzed using Chi-square test, fisher exact test\& paired t-test. The critical value of the tests "P" was considered statistically significant when $\mathrm{P}$ less than 0.05 .

\section{Results:}

Table (1): Personal characteristics of the studied group $(\mathrm{No}=60)$ for hepatic encephalopathy.

\begin{tabular}{|c|c|c|}
\hline & No. $(n=60)$ & $\%$ \\
\hline \multicolumn{3}{|l|}{ Age: } \\
\hline$<55$ years & 16 & 26.7 \\
\hline $55-60$ years & 25 & 41.7 \\
\hline$>60$ years & 19 & 31.7 \\
\hline Mean \pm SD (Range) & \multicolumn{2}{|c|}{$58.07 \pm 6.91(39-75)$} \\
\hline
\end{tabular}


Table (2) : clinical data of the studied group $(\mathrm{No}=60)$ for hepatic encephalopathy.

\begin{tabular}{|c|c|c|c|}
\hline & $\mathbf{1}^{\text {st }}$ day & $2^{\text {nd }}$ day & P-value \\
\hline \multicolumn{3}{|c|}{ Abdominal girth: (cm) } & \multirow{3}{*}{$0.004 *$} \\
\hline Mean \pm SD & $95.40 \pm 10.62$ & $96.51 \pm 10.64$ & \\
\hline Range & $75-137$ & $75-137$ & \\
\hline \multicolumn{3}{|c|}{ West haven criteria: } & \multirow{3}{*}{$0.000 *$} \\
\hline Mean \pm SD & $3.22 \pm 0.76$ & $1.77 \pm 1.38$ & \\
\hline Range & $1-4$ & $0-4$ & \\
\hline \multicolumn{3}{|l|}{ Ascites: No. (\%) } & \multirow{3}{*}{--} \\
\hline Yes & 91.7 & -- & \\
\hline No & 8.3 & -- & \\
\hline
\end{tabular}

Paired T-test $\quad$ SStatistical significant difference

Table (3): Precipitating factors of the studied group (No = 60) for hepatic encephalopathy.

\begin{tabular}{|l|c|c|}
\hline \multicolumn{1}{|c|}{ Precipitating factors } & No. $(\mathbf{n}=\mathbf{6 0})$ & \% \\
\hline Constipation & 9 & 15.0 \\
\hline Diarrhea & 6 & 10.0 \\
\hline Excess protein load & 21 & 35.0 \\
\hline Excessive diuresis & 4 & 6.7 \\
\hline Fever & 1 & 1.7 \\
\hline Fluid restriction & 6 & 10.0 \\
\hline Gastrointestinal bleeding & 10 & 16.7 \\
\hline Paracentesis & 1 & 1.7 \\
\hline Vomiting & 2 & 3.3 \\
\hline
\end{tabular}

Table (4): Vital signs of the studied group $($ No $=60)$ for hepatic encephalopathy.

\begin{tabular}{|c|c|c|c|}
\hline & $1^{\text {st }}$ day & $2^{\text {nd }}$ day & P-value \\
\hline \multicolumn{3}{|c|}{ Temperature: ${ }^{\circ} \mathrm{C}$} & \multirow{3}{*}{0.185} \\
\hline Mean \pm SD & $37.19 \pm 0.37$ & $37.12 \pm 0.25$ & \\
\hline Range & $36.2-38.2$ & $36.5-37.7$ & \\
\hline \multicolumn{3}{|c|}{ Pulse: b/m } & \multirow{3}{*}{0.802} \\
\hline Mean \pm SD & $92.33 \pm 9.64$ & $92.02 \pm 8.68$ & \\
\hline Range & $71.0-120.0$ & $73.0-112.0$ & \\
\hline \multicolumn{3}{|c|}{ Respiration: $b / \mathbf{m}$} & \multirow{3}{*}{$0.050^{*}$} \\
\hline Mean \pm SD & $23.25 \pm 4.76$ & $22.00 \pm 2.50$ & \\
\hline Range & $18.0-41.0$ & $16.0-32.0$ & \\
\hline \multicolumn{3}{|c|}{ Mean arterial pressure: $\mathrm{mmHg}$} & \multirow{3}{*}{0.190} \\
\hline Mean \pm SD & $85.30 \pm 11.77$ & $83.75 \pm 7.84$ & \\
\hline Range & $63.0-116.0$ & $68.0-106.0$ & \\
\hline
\end{tabular}

Paired T-test

*Statistical significant difference 
Table (5): Arterial blood gases of the studied group $($ No $=60)$ for hepatic encephalopathy.

\begin{tabular}{|c|c|c|c|}
\hline & $\overline{1^{\text {st }} \text { day }}$ & $2^{\text {nd }}$ day & P-value \\
\hline \multicolumn{3}{|l|}{ PH: } & \multirow{3}{*}{0.386} \\
\hline Mean \pm SD & $7.47 \pm 0.07$ & $7.46 \pm 0.06$ & \\
\hline Range & $7.1-7.6$ & $7.3-7.6$ & \\
\hline \multicolumn{3}{|l|}{$\mathrm{PaO}_{2}$ : } & \multirow{3}{*}{0.863} \\
\hline Mean \pm SD & $101.93 \pm 37.67$ & $103.11 \pm 32.48$ & \\
\hline Range & $47.0-204.0$ & $35.0-167.0$ & \\
\hline \multicolumn{3}{|l|}{$\mathrm{PaCO}_{2}:$} & \multirow{3}{*}{0.110} \\
\hline Mean \pm SD & $29.01 \pm 5.73$ & $30.26 \pm 6.01$ & \\
\hline Range & $17.2-50.1$ & $17.1-47.1$ & \\
\hline \multicolumn{3}{|l|}{$\mathrm{HCO}_{3}:$} & \multirow{3}{*}{0.550} \\
\hline Mean \pm SD & $21.90 \pm 5.20$ & $21.41 \pm 4.72$ & \\
\hline Range & $9.8-34.8$ & $12.0-30.0$ & \\
\hline
\end{tabular}

Paired T-test

Table (6): Fluid intake, fluid output and enema of the studied group $($ No $=60)$ for hepatic encephalopathy.

\begin{tabular}{|c|c|c|c|c|c|}
\hline & \multicolumn{2}{|c|}{ 1 $^{\text {st }}$ day } & \multicolumn{2}{|c|}{$2^{\text {nd }}$ day } & P-value \\
\hline \multicolumn{5}{|c|}{ Fluid intake: $(\mathrm{ml})$} & \multirow{3}{*}{$0.000^{*} \#$} \\
\hline Mean \pm SD & \multirow{2}{*}{\multicolumn{2}{|c|}{$\frac{1150.42 \pm 696.55}{3750-37000}$}} & \multicolumn{2}{|c|}{$2095.00 \pm 766.55$} & \\
\hline Range & & & \multicolumn{2}{|c|}{$400.0-4050.0$} & \\
\hline \multicolumn{5}{|c|}{ Fluid output: (ml) } & \multirow{3}{*}{$0.000 * \#$} \\
\hline Mean \pm SD & \multicolumn{2}{|c|}{$558.33 \pm 341.88$} & \multicolumn{2}{|c|}{$1105.00 \pm 588.50$} & \\
\hline Range & \multicolumn{2}{|c|}{$0.0-1700.0$} & \multicolumn{2}{|c|}{$300.0-3600.0$} & \\
\hline \multicolumn{5}{|l|}{ Enema: No. (\%) } & \multirow{3}{*}{$0.648 \bullet$} \\
\hline Yes & 57 & 95.0 & 58 & 96.7 & \\
\hline$\overline{\text { No }}$ & 3 & 5.0 & 2 & 3.3 & \\
\hline
\end{tabular}

Paired T-test (\#) $\quad$ Fisher Exact test $(\bullet) \quad$ *Statistical significant difference

Table (7) : Complete blood picture of the studied group $(\mathrm{No}=60)$ for hepatic encephalopathy.

\begin{tabular}{|c|c|c|c|}
\hline & $1^{\text {st }}$ day & $2^{\text {nd }}$ day & P-value \\
\hline \multicolumn{3}{|l|}{ WBCs: } & \multirow{3}{*}{$0.033^{*}$} \\
\hline Mean \pm SD & $8.82 \pm 3.99$ & $7.89 \pm 4.67$ & \\
\hline Range & $2.7-19.4$ & $2.5-22.0$ & \\
\hline \multicolumn{3}{|l|}{ RBCs: } & \multirow{3}{*}{0.268} \\
\hline Mean \pm SD & $3.59 \pm 0.84$ & $3.51 \pm 0.92$ & \\
\hline Range & $1.8-5.8$ & $1.8-5.3$ & \\
\hline \multicolumn{3}{|l|}{ Hb: } & \multirow{3}{*}{0.133} \\
\hline Mean \pm SD & $10.78 \pm 2.61$ & $10.56 \pm 2.58$ & \\
\hline Range & $4.6-16.0$ & $4.8-16.5$ & \\
\hline \multicolumn{3}{|l|}{ Platelets: } & \multirow{3}{*}{$0.001 *$} \\
\hline Mean \pm SD & $109.99 \pm 47.24$ & $93.36 \pm 48.14$ & \\
\hline Range & $20.0-256.0$ & $19.1-257.0$ & \\
\hline \multicolumn{3}{|c|}{ Hepatitis markers: } & \multirow{3}{*}{--} \\
\hline $\mathrm{B}$ & 5.0 & -- & \\
\hline $\mathrm{C}$ & 95.0 & -- & \\
\hline
\end{tabular}

Paired T-test

*Statistical significant difference $(\mathbf{P}<\mathbf{0 . 0 5})$ 
Table (8) : Nutrition assessment for hepatic encephalopathy of the studied group (No=60).

\begin{tabular}{|c|c|c|c|c|c|}
\hline & \multicolumn{2}{|c|}{$1^{\text {st }}$ day } & \multicolumn{2}{|c|}{$2^{\text {nd }}$ day } & P-value \\
\hline \multicolumn{5}{|l|}{ Weight: } & \multirow{3}{*}{0.343} \\
\hline Mean \pm SD & \multicolumn{2}{|c|}{$64.92 \pm 6.38$} & \multicolumn{2}{|c|}{$67.35 \pm 13.05$} & \\
\hline Range & \multicolumn{2}{|c|}{$50.0-76.0$} & \multicolumn{2}{|c|}{$45.0-110.0$} & \\
\hline \multicolumn{5}{|l|}{ BMI: } & \multirow{3}{*}{0.330} \\
\hline Mean \pm SD & \multirow{2}{*}{\multicolumn{2}{|c|}{$\begin{array}{c}22.55 \pm 1.83 \\
19.5-25.7\end{array}$}} & \multicolumn{2}{|c|}{$24.20 \pm 5.30$} & \\
\hline Range & & & \multicolumn{2}{|c|}{$17.1-51.6$} & \\
\hline \multicolumn{5}{|l|}{ MAC: } & \multirow{3}{*}{0.532} \\
\hline Mean \pm SD & \multicolumn{2}{|c|}{$25.03 \pm 3.53$} & \multicolumn{2}{|c|}{$25.00 \pm 3.65$} & \\
\hline Range & \multicolumn{2}{|c|}{$18.0-35.0$} & \multicolumn{2}{|c|}{$18.0-35.0$} & \\
\hline \multicolumn{5}{|l|}{ TSFT: } & \multirow{3}{*}{0.322} \\
\hline Mean \pm SD & \multicolumn{2}{|c|}{$8.28 \pm 4.75$} & \multicolumn{2}{|c|}{$8.40 \pm 4.89$} & \\
\hline Range & \multicolumn{2}{|c|}{$5.0-30.0$} & \multicolumn{2}{|c|}{$5.0-30.0$} & \\
\hline \multicolumn{5}{|l|}{ SGA: } & \multirow{4}{*}{--} \\
\hline Well nourished & 7 & 11.7 & -- & -- & \\
\hline Mildly-moderately malnourished & 30 & 50.0 & -- & -- & \\
\hline Severely malnourished & 23 & 38.3 & -- & -- & \\
\hline
\end{tabular}

\section{Paired T-test}

BMI: Body mass index,

MAC: Mid arm circumference

TSFT: Triceps skin fold thickness

SGA: Subjective global assessment

Table (9) : Assessment of gastrointestinal complications for hepatic encephalopathy of the studied group $(\mathrm{No}=60)$.

\begin{tabular}{|l|c|c|c|c|c|}
\hline \multirow{2}{*}{ Complications } & \multicolumn{2}{|c|}{$\mathbf{1}^{\text {st }}$ day } & \multicolumn{2}{c|}{$\mathbf{2}^{\text {nd }}$ day } & \multirow{2}{*}{ P-value } \\
\cline { 2 - 5 } & No. & \% & No. & \% & \\
\hline Vomiting & 6 & 10.0 & 3 & 5.0 & 0.488 \\
\hline Constipation & 5 & 8.3 & 0 & 0.0 & 0.068 \\
\hline Diarrhea & 6 & 10.0 & 2 & 3.3 & 0.272 \\
\hline Hematemsis & 6 & 10.0 & 1 & 1.7 & 0.119 \\
\hline Melena & 8 & 13.3 & 8 & 13.3 & -- \\
\hline Bleeding per rectum & 0 & 0.0 & 0 & 0.0 & -- \\
\hline
\end{tabular}

\section{Fisher Exact test}

Figure (1): Distribution of the studied group according to outcome for hepatic encephalopathy

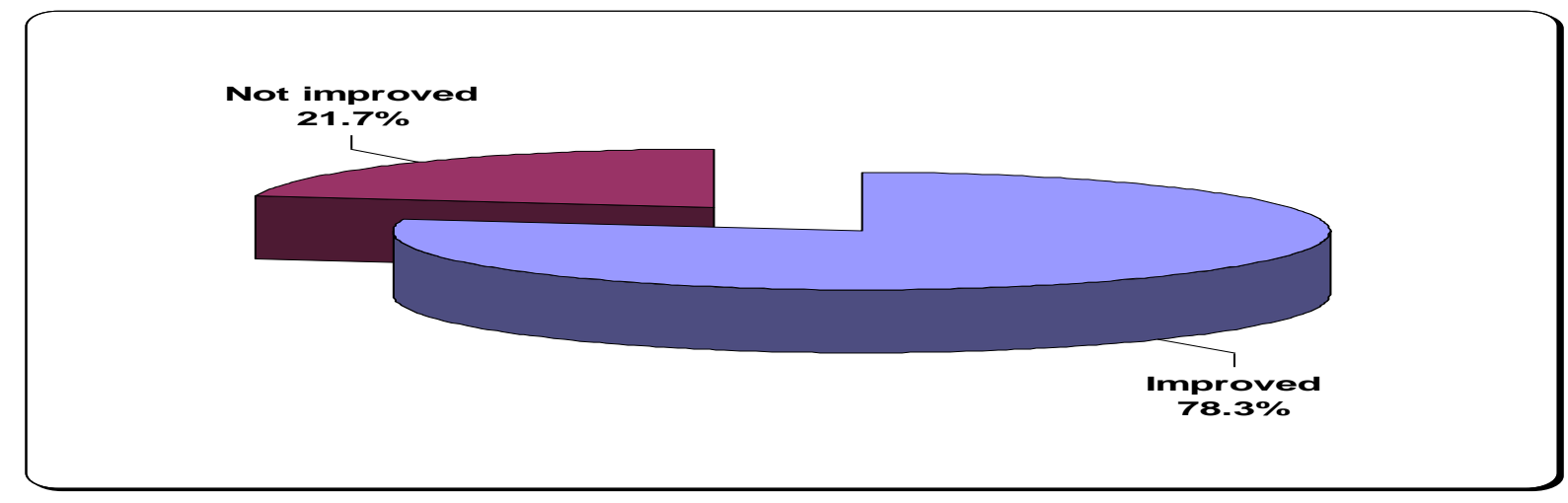


Table (1) : Shows that, the mean and standard deviation of age of the studied group $(\mathrm{N}=60)$ was found $(58.07 \pm 6.91)$

Table (2) : Regarding the clinical data of the studied group $(\mathrm{N}=60)$ : abdominal girth , for $2^{\text {nd }}$ day had wider girth $(96.51 \pm 10.64)$ than the $1^{\text {st }}$ day $(95.40 \pm$ 10.62) respectively. There were statistical significance differences were found between the two days with ( $\mathrm{p}$ value $=0.004)$.

Regarding West- haven criteria there was a significant decrease for the studied group $(\mathrm{N}=60)$ from $1^{\text {st }}$ day and $2^{\text {nd }}$ day. There were statistical significance differences between the two days with ( $p$ value $=0.000)$.

Regarding ascites $91.7 \%$ of patients had ascites and $8.3 \%$ didn't have ascites for the studied group $(\mathrm{No}=$ 60) .

Table (3) : Regarding the precipitating factors for hepatic encephalopathy; excess protein intake was the most common precipitant factor $35 \%$ of cases. Gastrointestinal bleeding was second most common cause of hepatic encephalopathy $16.7 \%$ of cases. Constipation was the third factor $15 \%$ of cases. Diarrhea was the fourth in the list of precipitating factors $10 \%$ of cases.

Table (4) : Regarding vital signs: body temperature, pulse\& mean arterial pressure. There were no statistical significant differences between both days of the studied group $(\mathrm{No}=60)$. Regarding respiration, there was a significant difference between the mean respiration in $1^{\text {st }} \& 2^{\text {nd }}$ day in the studied group ( $p$ value $=0.050)$

Table (5) : showed that studied patients in $2^{\text {nd }}$ day had experienced increase in partial arterial $\operatorname{oxygen}(\mathbf{p o 2})$ with mean and standard deviation(103.11 \pm 32.48) and statistical not significant difference was found between both days with $(p=0.863)$. Regarding the level of PH had decreased in $2^{\text {nd }}$ day with mean and standard deviation (7.46 \pm 0.06$)$ and statistical not significant difference was found between both days with $(\mathrm{p}=$ 0.386)

Regarding the level of bicarbonate (HCO3) in blood had decreased in $2^{\text {nd }}$ day with mean and standard deviation $(21.41 \pm 4.72)$. Concerning carbon dioxide had increased in $2^{\text {nd }}$ day, there was statistical not significant difference between the studied group in $2^{\text {nd }} \operatorname{day}(\mathrm{p}=0.110)$.

Table (6) : Regarding fluid intake, the mean and standard deviation of fluid intake\& output showed that significant increase on $2^{\text {nd }}$ day $(209 \pm 766.55$ $\& 1105 \pm 588.50)$ were recorded ( $\mathrm{p}$ value $=0.000$ )

Table (7) : Regarding complete blood picture; white blood cells, the mean value of WBCs showed that significant decrease on $2^{\text {nd }}$ day $(7.89 \pm 4.67)$ was recorded $(p$ value $=0.033)$. Regarding platelets, the mean value of platelets showed that significant decrease on $2^{\text {nd }}$ day $(93.36 \pm 48.14)$ was recorded ( $p$ value $=0.001)$. Regarding hepatic markers; $95 \%$ of cases had hepatitis $\mathrm{C}$ while $5 \%$ of cases had hepatitis B.

Table (8) : Regarding the nutrition assessment: The mean value of weight, body mass index, mid arm circumference and triceps skin fold thickness showed no significant difference. Regarding subjective global assessment, seven patients were well nourished, thirty patients were mild-moderate mal nourished and twenty three patients were severe mal nourished.

Table (9) : Regarding assessment of gastrointestinal complication: vomiting, constipation, diarrhea and hematemesis decreased in $2^{\text {nd }}$ day and there were no significant differences in the studied patients.

Figure (1) : Regarding Outcome: $78.3 \%$ of patients improved and $21.7 \%$ of patients not improved in the studied patients.

\section{Discussion:}

Hepatic encephalopathy is a state of disordered central nervous system function resulting from failure of the liver to detoxify noxious agents of gut origin because of hepatocellular dysfunction and Porto systemic shunting. The clinical scale ranges from day-night reversal and mild intellectual impairment to coma. Patients with minimal hepatic encephalopathy have no recognizable clinical symptoms but show mild cognitive and psychomotor deficits and attention deficits on standardized tests and an increased rate of traffic accidents (Lawrence \& Friedman 2010). The stages of overt encephalopathy are mild confusion, drowsiness , stupor, and coma (Jones, 2000) .

immediate care describe the minimal requirements that define an acceptable level of care, which is to exercise ordinary and reasonable care to see that no unnecessary harm comes to the patient (Guido, 2006).'Hence the present study aims to assess the immediate nursing care for hepatic encephalopathy patients to reduce gastrointestinal complication on patients outcome among the critically ill patient at main Assiut university hospital.

The present study showed that the majority of the studied group were in age group Maximum age was 75 years and minimum was 39 years with mean and standard deviation of this age $(58.07 \pm 5.91)$. This is in agreement with ( Durrani et al 2001, Maqsood et al 2006 \&Zakaria et al 2008 ). who reported that the age was more than forty years old.

(Smeltzer et al, 2008) mentioned that increased abdominal girth and rapid weight gain are common 
presenting symptoms of ascites. The patient may be short of breath and uncomfortable from the enlarged abdomen, and distended veins may be visible over the abdominal wall.

The current study showed significant difference regard abdominal girth between $1^{\text {st }}$ days 2 nd day.

It is important to assess the degree of $\mathrm{HE}$ and to quantify the effect of therapeutic interventions in a reliable and reproducible manner. However, as noted 20 years ago, there is no standardized method. In spite of the important progresses of neurological techniques, specially for neuroimaging methods ( Cordoba et al, 2002). Clinical scales are commonly considered the best way to assess the degree of impairment and have its impact on daily life activities for the majority of neurological diseases. Similarly, a consensus group recommended using clinical scales for grading episodic encephalopathy and to report efficacy in therapeutic trials. The same group proposed to use the West-Haven criteria to classify the severity of HE (Ferenci et al, 2002).

Regarding the precipitating factors for hepatic encephalopathy, the present study revealed that excess protein load was the most common precipitant factor $35 \%$ of cases. Gastrointestinal bleeding was second most common cause of hepatic encephalopathy $16.7 \%$ of cases. Constipation was the third factor $15 \%$ of cases. Diarrhea was the fourth in the list of precipitating factors $10 \%$ of cases. This result disagreement with (Hammed et al, 2001and Sheikh et al, 2001). Who reported that the earlier studies in developing countries found upper gastrointestinal (GI) bleeding to the most common precipitant for $\mathrm{HE}$ in $56 \%$ and $67 \%$ in their series.

(Comer , 2005) reported that nursing interventions to support adequate respiratory function are individualized to meet hepatic encephalopathy patient needs. Which include frequent assessment of airway patency and function, suctioning, patients mobility, positioning of the patient to prevent accumulation of secretions and encouraging deep breathing.

Regarding fluid intake, the mean and standard deviation of fluid intake\& output showed that significant increase on $2^{\text {nd }}$ day $(209 \pm 766.55 \& 1105 \pm$ 588.50 ) were recorded ( $\mathrm{p}$ value $=0.000$ ).

Regarding complete blood picture; white blood cells , the mean value of WBCs showed that significant decrease on $2^{\text {nd }}$ day $(7.89 \pm 4.67)$ was recorded $(\mathrm{P}=$ 0.033). Regarding platelets, the mean value of platelets in the studied group $(\mathrm{No}=60)$ showed that significant decrease on $2^{\text {nd }}$ day $(93.36 \pm 48.14)$ was recorded $(\mathrm{p}$ value $=0.001)$. Regarding hepatic markers; $95 \%$ of cases had hepatitis $\mathrm{C}$ while $5 \%$ of cases had hepatitis B.
Nardi et al, (2009) stated that, skin fold anthropometry is considered a useful technique for assessment of body composition in patients with chronic liver disease. It is value in detecting mild or moderate of signs of malnutrition, which are difficult to recognize clinically. Caregaro et al, (1996) stated that because of limitations of other nutritional indexes, skin fold anthropometry represents the most reliable clinical measure of nutritional status in patients with chronic liver disease. Its correlation with survival could be used to improve the accuracy of the commonly used prognostic formulas.

Carvalho and Rober (2006) stated that alteration of the anthropometric and biochemical parameters of the cirrhotic patients based on TSFT values, the groups already presented a $50 \%$ loss of fat reserves regardless of etiology of the disease.

The present study revealed that, the majority of both study and control group had moderate to severe malnutrition according to Triceps Skin Fold Thickness (TSFT) measurement . The results of the present study are supported by Riggio et al, (2003) and Fyke, (2004) who stated that, there is an increased risk of malnutrition associated with liver cirrhosis, therefore cirrhotic patients may lose their weight rapidly and become susceptible to because they cannot absorb malnutrition valuable vitamins, calorie, and iron.

Demling and Desanti (2004) reported that MAC and TSFT are useful in identifying the most severely malnourished patients especially those with fluid retention as a result of disease. On the other hand American physician family ,(2003) reported that mild to moderate protein calorie malnutrition was found in liver cirrhosis, adults generally lose their body weight although edema may mask weight loss, triceps skin fold thickness and mid arm muscle area are reduced below normal range.

BMI measurements in less malnourished cirrhotic patients were not different from the general population, mainly due to the fact that ascites and peripheral oedema contributed significantly to body weight in cirrhotic patients, and true lean body mass was not taken into account (Campillo et al, 2006).

Roongpisuthiponget al, (2001) reported that Subjective Global Assessment compared to standard anthropometry, is much more applicable in clinical practice and has previously been demonstrated to be highly predictive of malnutrition in advanced cirrhosis .

\section{Conclusions:}

Applied immediate nursing care significant to reduce gastrointestinal complication in hepatic 
encephalopathy patients and improve the patient's outcome.

\section{Recommendations:}

Based on the finding of the current study, the following recommendations are suggested:

1- Provide nutritional counseling for all patients with hepatic encephalopathy in the hospital.

2- Develop educational nursing programmes to access the high quality of care.

3- Equip the intensive care unit of gastroenterology and hepatology with simple illustrated standards nursing car for hepatic encephalopathy patients.

\section{Referrences:}

1. American Physician Family, (2003): Management challenges of liver cirrhosis, available at : http://www. Pubmed.Com.

2. Bacon B., O'grady J., Bisceglie A.,\& Lake J., (2006): Clinical Hepatology $2^{\text {nd }}$ ed. China: Elsevier Mosby, Ch(11), Pp. 169.

3. Bajaj JS. (2010): Review article: the modern management of hepatic encephalopathy. Aliment. Pharmacol. Ther. 31 (5):537-547.

4. Campillo B., Richardet J., and Bories P., (2006): Validation of body mass index for the diagnosis of malnutrition in patients with liver cirrhosis, Gastroenterology, Clinical Biology, (30), Pp. 1137-1143.

5. Caregaro L., Alberino F., Amodio P, Merkel C, Bolognesi $M$ and Angeli P.(1996): Malnutrition in alcoholic and virus related cirrhosis American journal of Clinical Nutrition,(63), Pp. 602-609. Available at: http://www.ajcn.org. by guest on July 8,2011.

6. Carvalho L., and Rober E., (2006): Evaluation of nutritional status for non hospitalized patients with liver cirrhosis, Gastroenterology, (43)10, Pp. 320-328.

7. Comer S., (2005): Delmar,s Critical Care Nursing Care Plans, 2 ${ }^{\text {nd }}$ Edition, united state; Thoson, Pp 220-227.

8. Cordoba J., Sanpedro F., Alonso J., and Rovira A. (2002): 1H-magnetic resonance in the study of hepatic encephalopathy in humans. Metab Brain Dis; 17: 415-29.

9. Demling R., and Desanti L., (2004): Involuntary weight loss and protein energy malnutrition, diagnosis and treatment, available at http://wwwMSN.Com.

10. Dooley J., Lok A., \& Burraughs A., (2011): Sherlock's disease of the liver and Biliary system $12^{\text {th }}$ ed., Wiley Blackwell, Singapore: $\mathrm{Ch}(8)$, Pp.121-144.
11. Durrani A., Rana A ., Siddiqi H., \& Marwat B., (2001): The spectrum of chronic liver disease in Balochistan. J Coll Physician Surg Pak; 11(2): 95-97.

12. Ferenci P., Lockwood A, Mullen K, Tarter R, Weissenborn K\& Blei A., (2002): Hepatic encephalopathy-definition, nomenclature, diagnosis, and quantification: final report of the working party at the $11^{\text {th }}$ world congress of gastroenterology. Vienna, 1998. Hepatology 35(3):716-21.

13. Fyke M., (2004): Malnutrition, available at http://www.Medscape.Com.

14. Garcia-Tsao G., and Lim J., (2009): Management and treatment of patients with cirrhosis and portal hypertension: recommendations from the Department of Veterans Affairs Hepatitis C Resource Center Program and the National Hepatitis C Program. Am J Gastroenterol 104(7):1802-29. [Context Link]

15. Guido G., (2006): Legal and ethical issues in nursing $4^{\text {th }}$ ed. United States of America: Pearson Prentice Hall, Ch(4), Pp. 55-56.

16. Hameed A., Masood R \& Liyas S., (2001): Factors precipitating hepaticencephalopathy in liver cirrhosis. J Postgrad Med; 15:91-7.

17. Hickey J., (2003): The clinical practice of neurologic and neuro surgical nursing $5^{\text {th }}$ ed. Philodelphia: Lippincott Williams\& Wilkins.

18. Jones E., (2000): Pathogenesis of hepatic encephalopathy. Clinics in Liver Disease; 4:467485.

19. Lawrence S., \& Friedman. (2010): Liver, Biliary Tract, \& Pancreas Disorders. In: Current Medical Diagnosis \& Treatment. 49th edition: Mc Graw Hil Lange; 622-23.

20. Lewis S., Heitkemper M., \& Dirksen S., (2007): Medical surgical Nursing assessment and management of clinical problems. $7^{\text {th }}$ ed. st louin: Mosby, ch (44): Pp: 1101-1102.

21. Maqsood S., Saleem A., Iqbal A., \& Butt J., (2006): Precipitating factors of hepatic encephalopathy: Experience at Pakistan Institute Of Medical Sciences Islamabad J Ayub Med Coll Abbottabad Oct - Dec;18(4):57-61.

22. Mc Conville P., Mc Dermott E., \&M., Cormick P., (2010): "current concepts in the assessment and treatment of hepatic encephalopathy". QJM 103(1) : 9-16.

23. Nardi M., Ognana G., Schiva G., and Caregaro L. (2009): Nutritional support in liver cirrhosis, journal of Nutritional Therapy and Metabolism, (27), Pp. 155-163. Clinical Nutrition unit, Department of Clinical and 
Experimental Medicine, university of Padua, Padua-Italy.

24. Prakash R., \& Mullen K., (2010): Mechanisms, diagnosis and management of hepatic encephalopathy. Nat Rev Gastroenterology Hepatology.7(9): 515-525.

25. Riggio O., Angelonis S, Nicolini G., Attili A., Albanese $C$ and Merli M.(2003): Malnutrition is not related to alternations in energy balance in patients with stable liver cirrhosis, Clinical Nutrition(9), Pp. 22-553.

26. Roongpisuthipong C., Sobhonslidsuk A., Nantiruj $K$ and Songchitsomboon S. (2001): Nutritional assessment in various stages of liver cirrhosis. Nutrition, 17(9):761-765.

27. Sheikh A., Ahmed SI\& Nassemullah M., (2001): Etiology of hepatic encephalopathy and Importance of upper gastrointestinal bleeding and infections precipitating factors. J Rawalpindi Med Coll; 5:10-2.

28. Smeltzer S., Bare B., Hinkle J., \&Cheever K., (2008): Brunner\& Suddarth,s Text book of Medical-Surgical Nursing. Lippincott Williams \&Wilkins; United States of American Ch(39) Pp. 1306-1307.

29. Zakaria M., Hussain S., Rehman M., Butt A\& Rana G F. (2008): Hepatic encephalopathy; precipitating factors in patients with cirrhosis Professional Med J Jul - Sep;15(3):375-9. 